\title{
Laser Damage Testing of Small Optics for the National Ignition Facility
}

R. Chow, M. Runkel, J.R. Taylor

January 27, 2004

OSA Optical Interference Coatings, Tucson, AZ June 27 -July 2, 2004 
This document was prepared as an account of work sponsored by an agency of the United States Government. Neither the United States Government nor the University of California nor any of their employees, makes any warranty, express or implied, or assumes any legal liability or responsibility for the accuracy, completeness, or usefulness of any information, apparatus, product, or process disclosed, or represents that its use would not infringe privately owned rights. Reference herein to any specific commercial product, process, or service by trade name, trademark, manufacturer, or otherwise, does not necessarily constitute or imply its endorsement, recommendation, or favoring by the United States Government or the University of California. The views and opinions of authors expressed herein do not necessarily state or reflect those of the United States Government or the University of California, and shall not be used for advertising or product endorsement purposes. 


\title{
Laser damage testing of small optics for the National Ignition Facility
}

\author{
Robert Chow, Mike Runkel, John R. Taylor \\ Lawrence Livermore National Laboratory, Livermore, California \\ Chow3@llnl.gov
}

\begin{abstract}
A damage test procedure was established for optical components that have large incident beam footprints. The procedure was applied on coated samples for a high powered 1053 $\mathrm{nm}$, 3-ns pulse length laser system.
\end{abstract}

OICS codes: 140.3330 (Laser damage); 220.4840 (Optical testing); 310.6870 (Thin films, other properties)

Summary: The National Ignition Facility (NIF) will be a 1.8 MJ class laser at Lawrence Livermore National Laboratory (LLNL). A laser damage test procedure has been developed for high fluence optics that are less than $150 \mathrm{~mm}$ in diameter. The test and detection methodology was developed in-house and transferred to two commercial suppliers of laser damage test services. Coated samples were tested in a damage testing facility at LLNL and also provided to the commercial test services for damage testing according to the NIF test procedure. The data and analysis used to support the certification of the commercial test services is described. Table 1 shows a positive correlation (Degree-of-Fit) between thresholds from the commercial services and those thresholds obtained at LLNL. Another criteria was used that accounted for the measurement errors, and the results tabulated as the number of "accepted points" for each category of coating.

Table 1 Laser damage threshold correlation to data of the LLNL pre-tested samples.

\begin{tabular}{|l|c|c|c|c|}
\hline Coating Type & $\begin{array}{c}\text { Test Service A } \\
\text { Degree of Fit }\end{array}$ & $\begin{array}{c}\text { Test Service A } \\
\text { Accepted points }\end{array}$ & $\begin{array}{c}\text { Test Service B } \\
\text { Degree of Fit }\end{array}$ & $\begin{array}{c}\text { Test Service B } \\
\text { Accepted points }\end{array}$ \\
\hline Anti-reflector & $41 \%$ & 7 of 9 & $65 \%$ & 7 of 9 \\
\hline High reflector & $98 \%$ & 9 of 9 & $79 \%$ & 8 of 9 \\
\hline Polarizer & $93 \%$ & 9 of 9 & $66 \%$ & 7 of 9 \\
\hline
\end{tabular}

Figure 1 below is the correlation plot of the high reflector thresholds from one of the commercial damage test services plotted against the pre-determined LLNL values.

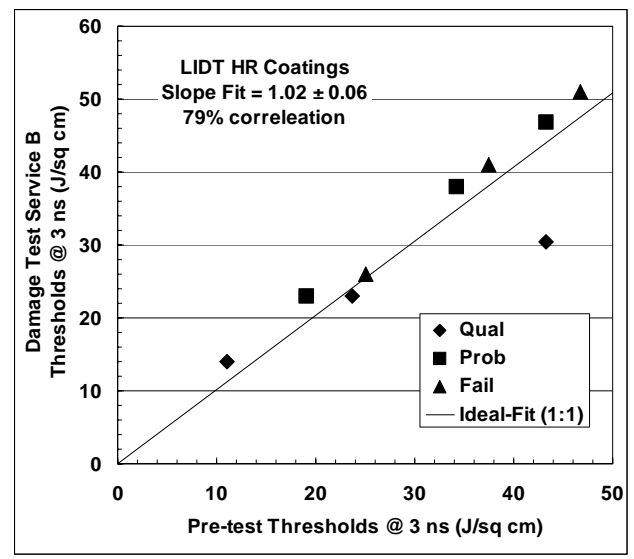

Fig. 1 Laser damage thresholds of high reflector coatings. The Ideal-fit line is also the 1:1 line. The pulse length exponent is zero for $1 \mathrm{w}$ high reflector coatings with a $45^{\circ}$ angle-of-incidence. 
The results of key procedural features that improve the quality of the laser damage thresholds are presented. One feature is the sampling of a large area of the clear aperture. Another feature is testing the anti-reflective coatings as the exit surface of the witness sample. Table 2 shows the damage thresholds of the same anti-reflective coatings tested identically but in one case the coating is the entrance surface and in the other case the coating is the exit surface. Testing of anti-reflective coatings as the exit surface provided a higher level of differentiation between a high and low laser damage coating.

Table 2 Comparison of Qualified laser damage thresholds. The thresholds are at $1064 \mathrm{~nm}$ and scaled to $3 \mathrm{~ns}$ pulse lengths. There is little variation in the survivability of the anti-reflective coatings when tested with frontside irradiation.

\begin{tabular}{|c|c|c|}
\hline AR coated Samples & Backside $(\mathrm{J} / \mathrm{sq} \mathrm{cm})$ & Frontside $(\mathrm{J} / \mathrm{sq} \mathrm{cm})$ \\
\hline 957603 & 23 & 23 \\
\hline 12030006 & 5 & 23 \\
\hline 12030023 & 2 & 25 \\
\hline
\end{tabular}

Exponents for pulse length scaling are reported for $1064 \mathrm{~nm}$ laser damage thresholds between 3 and $10 \mathrm{~ns}$ pulse lengths of dielectric coated optics. The exponents are 0.35 , zero, and 0.18 for anti-reflective, high reflector, and polarizer coatings, respectively.

Pre-tested coated samples were also tested according to the ISO10110 laser damage test procedure and the thresholds compared. Test results using the NIF procedure tended to be more conservative than when the ISO 10110 procedure was used. The conclusion is to damage test the witness samples with test conditions that simulate as closely as possible the operating conditions that the parts will undergo.

This work was performed under the auspices of the U. S. Department of Energy by the University of California Lawrence Livermore National Laboratory under Contract W-7405-Eng-48. (UCRL-CONF-155871) 